\title{
Fibroblast growth factor 7 , secreted by breast fibroblasts, is an interleukin-1 $\beta$-induced paracrine growth factor for human breast cells
}

\author{
C Palmieri, D Roberts-Clark, A Assadi-Sabet, R C Coope, \\ M O'Hare', A Sunters, A Hanby ${ }^{2}$, M J Slade, J J Gomm, \\ E W-F Lam and R C Coombes
}

\footnotetext{
Cancer Research UK Laboratories, Department of Cancer Medicine, MRC Cyclotron Building, Imperial College, Hammersmith Hospital, Du Cane Road, London W12 0NN, UK

${ }^{1}$ University College London Breast Cancer Laboratory, Department of Surgery, Royal Free and University College Medical School, Riding House Street, London W1W 7EJ, UK

${ }^{2}$ Hedley Atkins/ICRF Breast Pathology Laboratory, Guy's Hospital, St Thomas Street, London SE1 9RT, UK

(Requests for offprints should be addressed to R C Coombes, Cancer Research UK Laboratories and Section of Cancer Cell Biology, Department of Cancer Medicine, Imperial College, Hammersmith Hospital, Du Cane Road, London W12 0NN, UK; Email: c.coombes@ic.ac.uk)

(C Palmieri and D Roberts-Clark contributed equally to this work)
}

\begin{abstract}
Keratinocyte growth factor/fibroblast growth factor 7 (KGF/FGF7) is known to be a potent growth factor for mammary cells but its origin, cellular targets and mode of action in the breast are unclear. In this study, we carried out studies to determine the localisation of FGF7 and its receptor, and the related growth factor FGF10. We also determined the factors that regulate FGF7 release from stromal cells and the effects of FGF7 on normal and neoplastic breast cells. Using an FGF7-specific antibody which does not react with the FGF7 heparan sulphate proteoglycan (HSPG)-binding site, we showed epithelial and myoepithelial immunohistochemical staining in normal breast sections, and epithelial staining in breast carcinomas. Stromal staining was also detected in some lobular carcinomas as well as a subset of invasive ductal carcinomas. FGF10 and FGF receptor (FGFR)2 immunostaining showed a similar epithelial expression pattern, whereas no stromal staining was observed. We purified normal breast stromal, epithelial and myoepithelial cells and showed that FGF7 stimulated proliferation of both
\end{abstract}

epithelial cell types, but not stromal fibroblasts. We also examined the effects of FGF7 on Matrigel-embedded organoids, containing both epithelial and myoepithelial cells, and showed FGF7 induced an increase in cellular proliferation. Furthermore, conditioned medium derived from stromal cells was shown to increase the proliferation of normal and neoplastic breast epithelial cells, which could be abolished by a neutralising antibody to FGF7. Finally, we showed that interleukin- $1 \beta$, but not oestradiol or other oestrogen receptor ligands, caused a dose-related FGF7 release. Further results also indicate that the epithelial localisation of FGF7 and FGF10 in breast tissue sections is likely to be due to their binding to their cognate receptor. In summary, our findings suggest that FGF7 is a paracrine growth factor in the breast. FGF7 is produced by the breast stromal fibroblasts and has profound proliferative and morphogenic roles on both epithelial and myoepithelial cells.

Journal of Endocrinology (2003) 177, 65-81

\section{Introduction}

Keratinocyte growth factor/fibroblast growth factor 7 (KGF/FGF7) is one of the family of FGFs, which comprises over 22 members, including FGF1 (acidic), FGF2 (basic), FGF3 (int2), FGF4 (hst), FGF5, FGF6, FGF8 (AIGF) and FGF9 (GAF) (Basilico \& Moscatelli 1992, Tanaka et al. 1992, Miyamoto et al. 1993), of which FGF10 (KGF2) and FGF11-20 were identified by a combination of random cDNA sequencing, database searches and homology-based PCR (Nishimura et al. 1993, Yamasaki et al. 1996, Verdier et al. 1997, Hoshikawa et al. 1998, Ohbayashi et al. 1998, Koga et al. 1999). Amongst the known FGFs, FGF7 and FGF10 are unusual in that they have a stromal origin and appear to act specifically on epithelial cells and are therefore exclusively paracrine growth factors (reviewed in Rubin et al. 1995, Emoto et al. 1997). This is in contrast to other family 
members, such as FGF1 and FGF2, which target fibroblasts as well as epithelial cells and may act in both an autocrine and paracrine fashion.

FGF7 binds and activates a splice variant of the FGF receptor (FGFR) 2 (Miki et al. 1991). Alternative splicing of the C-terminal half of the third immunoglobulin-like domain changes the ligand-binding properties for FGFR2, leading to FGFR2-IIIb binding specifically to FGF10 and FGF7, and FGFR2-IIIc interacting preferentially with FGF1 and FGF2 (Yayon et al. 1992). Whereas epithelial cells express FGFR2-IIIb, cells of mesenchymal origin express FGFR2-IIIc (Pekonen et al. 1993, Savagner et al. 1994) and this is found to be the case in most epithelial organs, including the breast (Luqmani et al. 1996).

Reports published previously have documented the importance of FGF7 in controlling the growth of mammary epithelium. These include the report of Imagawa et al. (1994), who showed that FGF7 induced the growth of murine mammary epithelial cells in a collagen gel matrix in a heparin-independent manner, and the studies of Pekonen et al. (1993) which demonstrated that systemic administration of FGF7 to rats resulted in mammary ductal epithelial hyperplasia, with an excess of new duct formation. Histologically, these changes in female rats arose from the growth of new ducts lined by mitogenically active epithelium, resulting in hyperplasia which was so excessive that the lumena were often occluded. It has also been shown that the murine mammary gland can be stimulated to undergo lobular development in response to exogenous FGF7 (Cardiff \& Wellings 1999). Transgenic mice, in which FGF7 has been targeted to the breast under the control of the mouse mammary tumour virus (MMTV) long terminal repeat, showed high levels of the FGF7 transgene expression during pregnancy and lactation, and developed hyperproliferation of the end-buds and adenocarcinomas with high frequency (Kitsberg \& Leder 1996). Other transgenic studies have also demonstrated the importance of FGFR2-IIIb in mammary gland lobuloalveolar development and morphogenesis (Jackson et al. 1997).

Despite this, surprisingly no defect in the structure or function of the mammary gland was reported in mice homozygous for a null mutation in the FGF7 gene (Guo et al. 1996). However, overexpression of dominant negative FGFR2-IIIb was shown to impair lobulo-alveolar development, suggesting the existence of another ligand for this receptor (Jackson et al. 1997). FGF10 was found to fulfil the criteria for the alternative ligand (Hoshikawa et al. 1998). FGF10 and FGFR2-IIIb null mice have similar phenotypes. FGF10 null mice have also shown defective ductal branching and FGF10 appears to be important for a subset of placodes that give rise to the mammary glands in early embryonic development (Mann \& Borgen 1998).

Previous studies using PCR analysis by others (Jacquemier et al. 1998) and our group (Bansal et al. 1997) have demonstrated the presence of FGF7 mRNA in breast tissues. We have shown that FGF7 mRNA is present in stromal tissues but not in separated epithelial or myoepithelial cells. In contrast, FGFR2-IIIb mRNA was found at low levels in epithelial and myoepithelial cells but was absent from fibroblasts. FGF7 was also demonstrated to induce proliferation of breast cancer cells (Bansal et al. 1997). Conversely, Jacquemier et al. (1998) have demonstrated FGF7 protein associated with the most differentiated and least aggressive breast tumours. Despite these previous studies, the origin, cellular targets and mode of action of FGF7 in the breast remain unclear. Moreover, most of these former studies were carried out using RT-PCR methods, and the levels of protein expression and their activity were not defined.

The purpose of the present study was to localise FGF7, FGF10 and FGFR 2 proteins and their sites of expression in an extensive range of normal and malignant breast tissues and to elucidate their potential functions during normal mammary growth and cancer using pure populations of breast cells (i.e. fibroblasts, epithelial and myoepithelial cells). This report documents the release of FGF7 by mammary fibroblasts and its effects on breast cell lines, breast-derived ducto-lobular fragments (organoids) and purified breast epithelial and myoepithelial cells. We also demonstrate that stromal FGF7 expression is inducible by interleukin-1 $\beta$ (IL-1 $\beta$ ). Together these results lead us to hypothesise that FGF7 is likely to be important in the control of normal breast cell proliferation and mammary morphogenesis.

\section{Materials and Methods}

\section{Western blot analysis and antibodies}

Western blots were performed to examine the specificity of the available FGF7 and FGF10 antibodies: 1, 0.5, 0.25 or $0 \cdot 125 \mu \mathrm{g}$ of either recombinant FGF7 or FGF10 (R\&D Systems, Oxon, UK) was separated by SDS-PAGE, transferred to nitrocellulose membranes and recognised by specific antibodies. The rabbit polyclonal antibodies against FGF7 (C-19, H-73, N-14) and FGF10 (H-121) were purchased from Santa Cruz Biotechnology (Santa Cruz, CA, USA). The goat polyclonal (AF-251-NA) and mouse monoclonal (MAB251) FGF7 antibodies were acquired from R\&D Systems. The antibodies were detected using horseradish peroxidase (HRP)-linked goat anti-mouse or anti-rabbit IgG (Dako, Ely, UK), or mouseabsorbed goat anti-rat IgG (Southern Biotechnology Associates, Inc.) and visualised by the enhanced chemiluminescence detection system (Amersham Pharmacia Biotech). The FGF2R antibody (C-17) (Santa Cruz Biotechnology) used in this study has been shown to react with only the FGFR2-IIIb isoform but not the FGFR2IIIc expressed in fibroblasts. The specificity of the FGF2R antibody staining was verified by blocking with excess 
immunising peptide as recommended by the manufacturer (Santa Cruz Biotechnology).

\section{ELISAs}

ELISA was conducted to assess the potential inhibitory effect of heparin on the binding of different anti-FGF7 antibodies. To this end, FGF7 antibodies were used to detect recombinant FGF7 in the presence of increasing concentrations $(0,1,3,10$ or $30 \mu \mathrm{g} / \mathrm{ml})$ of either low molecular weight heparin, high molecular weight heparin or heparan sulphate (R\&D Systems). One microgram per millilitre recombinant FGF7 was incubated with either heparin or heparan sulphate for 90 min before loading on triplicate wells. After blocking with PBS containing 5\% (w/v) BSA for $90 \mathrm{~min}$, the primary FGF7 antibodies diluted to $0.5 \mu \mathrm{g} / \mathrm{ml}$ with the blocking solution were added to the wells and incubated for $2 \mathrm{~h}$ before being washed off with PBS three times. The HRP-conjugated secondary antibodies diluted 1:10 000 with blocking solution were added to the wells and incubated for $90 \mathrm{~min}$ prior to another three washes with PBS. The colorimetric substrate solution $3,3^{\prime}, 5,5^{\prime}$-tetramethylbenzadine (TMB peroxidase substrate 1-C; Kirkegaard and Perry Labs, Gaithersburg, USA) was then added to the wells, and colour development was allowed to proceed for $30 \mathrm{~min}$ before addition of the same volume of a 'stop' solution $\left(0 \cdot 18 \mathrm{M} \mathrm{H}_{2} \mathrm{SO}_{4}\right)$. The plate was read using a microplate reader within $30 \mathrm{~min}$ at a wavelength of $450 \mathrm{~nm}$. A standard curve for each ELISA experiment was prepared from triplicate wells containing either $0,1,0.5,0.25$ or $0.125 \mu \mathrm{g} / \mathrm{ml}$ recombinant FGF7 (R\&D Systems) using the protocol described above. As negative controls, the primary antibodies were omitted and replaced with PBS.

\section{Immunohistochemical staining and breast samples}

For immunohistochemical study of paraffin sections (with the H-73 antibody), we used 61 samples of normal breast (12 samples), fibrocystic disease (ten samples), hamartoma (three samples), duct ectasia (two samples), phylloides (three samples) and hyperplasia (two samples). For the breast carcinomas, we used samples from ductal carcinoma in situ (DCIS) (six samples), grade 1, 2 and 3 (six samples each), and lobular carcinoma in situ (LCIS) (five samples). Frozen sections from an additional 21 breast carcinomas, seven each of grades 1,2 and 3, and six samples of normal breast were also stained using similar methodology.

Immunostaining was performed on $4 \mathrm{~mm}$ paraffin waxembedded sections following dewaxing in xylene and rehydration with decreasing concentrations of alcohol. Following washing with PBS, sections were permeabilised in ice-cold 50\% (v/v) acetone followed by 100\% acetone. After extensive washing with PBS, these sections were then incubated with the pre-blocking solution consisting of PBS containing 5\% (w/v) BSA and 20\% $(\mathrm{v} / \mathrm{v})$ serum from the same species as the secondary antibodies for $1 \mathrm{~h}$ before incubation with the appropriate primary antibody at $5 \mu \mathrm{g} / \mathrm{ml}$ in pre-blocking solution. Controls were incubated with non-immune $\mathrm{IgG}$ from the same species as the primary antibodies at the same concentration and primary antibody pre-incubated with $40 \times(\mathrm{w} / \mathrm{w})$ excess immunising peptide (Santa Cruz Biotechnology) and $10 \times$ molar excess recombinant whole molecule ( $\& \& D$ Systems). Additionally, some control sections were incubated with primary antibody preincubated with a $10 \times$ molar excess of recombinant whole molecule $(\mathrm{FGFs})$ and a $10 \times$ molar excess of low molecular weight (molecular mass approximately $3000 \mathrm{Da}$ ) heparin (Sigma). Pre-incubations were carried out in $1.5 \mathrm{ml}$ microcentrifuge tubes overnight at $4{ }^{\circ} \mathrm{C}$.

After incubation overnight at $4{ }^{\circ} \mathrm{C}$, the primary antibodies were washed off with excess PBS, and the sections were incubated at room temperature for $90 \mathrm{~min}$ with HRP-conjugated secondary antibodies (Dako) diluted 1:250 with PBS containing 5\% BSA and 10\% human serum. After washing with PBS for $30 \mathrm{~min}$, the sections were incubated for 5 min with a $0.05 \% 3,3^{\prime}-$ diaminobenzidine (DAB)/0.01\% hydrogen peroxide solution (Dako) and washed for 2 min with tap water. The sections were then counterstained with Gill's haematoxylin for $10 \mathrm{~s}$, dehydrated in an increasing alcohol series, cleared with Histoclear (National Diagnostics, Hersle, UK) for $5 \mathrm{~min}$ three times and mounted with DPX Histomount (National Diagnostics).

\section{Growth assays}

The effect of FGF7 and fibroblast-conditioned medium (CM) (with or without $20 \mu \mathrm{g} / \mathrm{ml}$ of a neutralising antibody to FGF7 (R\&D Systems)) on primary breast cell proliferation was examined by growth assay methods described previously (Gomm et al. 1997). Briefly, purified epithelial and myoepithelial cells were seeded into duplicate 96-well plates and $200 \mu \mathrm{l}$ media were added. One plate was harvested prior to treatment and subsequently media were changed every 3 days. After 6-10 days of culture, cells were harvested and growth estimated using 3-(4,5dimethylthiazol-2-yl)-2,5-diphenyltetrazolium bromide (MTT) assays as previously described (Bansal et al. 1997, Gomm et al. 1997). The absorption was measured at $570 \mathrm{~nm}$ with a Model 550 microplate reader (Bio-Rad, Hemel Hempstead, Herts, UK).

\section{Organoid isolation and cultures}

To further examine the effect of FGF7 on primary breast cell proliferation, breast organoids (ductal and lobuloalveolar fragments) were prepared from reduction mammoplasty tissue as described previously (Gomm et al. 1995). Briefly, $0 \cdot 5 \mathrm{~cm}^{3}$ breast tissue was digested overnight with $1 \mathrm{mg} / \mathrm{ml}$ collagenase (Sigma) and $1 \mathrm{mg} / \mathrm{ml}$ hyaluronidase (Sigma) in RPMI 1640 (Gibco, Paisley, 
Strathclyde, UK) plus $5 \%$ fetal calf serum (FCS) at $37^{\circ} \mathrm{C}$, followed by centrifugation at $150 \mathrm{~g}$ for $5 \mathrm{~min}$. After removing the lipid layer, the tissue suspension was subjected to three sedimentations at $1 \boldsymbol{g}$ to enrich for the ductal and lobular elements. The supernatants containing single cells (including blood cells, as well as fibroblasts and endothelial cells) were removed and retained for breast stromal (fibroblast) cell culture. The enriched organoid preparation was centrifuged at $150 \mathrm{~g}$ for $5 \mathrm{~min}$ and resuspended in Matrigel basement membrane matrix (Becton Dickinson, Oxford, UK). Five hundred microlitres of suspension were added to several four-well glass Lab-Tek Chamber Slides (Nunc, Hereford, UK) and allowed to set at $37^{\circ} \mathrm{C}$ for $1 \mathrm{~h}$. When the Matrigel had set, $500 \mu \mathrm{l}$ warm breast culture medium (BCM) consisting of 1:1 mix of DMEM and Ham's F12 supplemented with $15 \mathrm{mM}$ Hepes, $2 \mathrm{mM}$ glutamine, $5 \mu \mathrm{g} / \mathrm{ml}$ insulin, $10 \mu \mathrm{g} / \mathrm{ml}$ apotransferrin, $100 \mu \mathrm{M}$ ethanolamine, $1 \mu \mathrm{g} / \mathrm{ml}$ hydrocortisone, $10 \mathrm{ng} / \mathrm{ml}$ epidermal growth factor (EGF), $100 \mathrm{U} / \mathrm{ml}$ penicillin, $0.1 \mathrm{mg} / \mathrm{ml}$ streptomycin, $50 \mathrm{U} / \mathrm{ml}$ polymyxin B and $2.5 \mu \mathrm{g} / \mathrm{ml}$ amphotericin (all from Sigma) (Gomm et al. 1995) were added to each well and the cultures were incubated at $37^{\circ} \mathrm{C}$. The following day, the organoid cultures were incubated with BCM with or without the addition of $20 \mathrm{ng} / \mathrm{ml}$ recombinant FGF7, FGF1 or FGF2 (R\&D Systems). Cultures were maintained for 2 weeks with media changes every other day. The mouse monoclonal FGF7-neutralising antibody (MAB251) was acquired from R\&D Systems. The 50\% neutralisation dose for this antibody has been determined as $1-2 \mu \mathrm{g} / \mathrm{ml}$ in the presence of $125 \mathrm{ng} / \mathrm{ml} \mathrm{FGF7.} \mathrm{These} \mathrm{neutralising} \mathrm{anti-}$ bodies are specific for their targets and have been extensively characterised by R\&D Systems. Neutralising antibodies were used at excess concentrations specified by the manufacturer (R\&D Systems): anti-FGF7 at $20 \mu \mathrm{g} / \mathrm{ml}$, anti-FGF1 at $100 \mu \mathrm{g} / \mathrm{ml}$ and anti-FGF2 at $50 \mu \mathrm{g} / \mathrm{ml}$.

The extent of organoid growth was gauged by two methods. First, the size of the organoids was measured by hand with a ruler on micrographs. Two diameters at right angles to each other were measured and the area calculated for each organoid. Secondly, for cell counting, at the end of the time course, the gels were washed with cold PBS and incubated with $2 \mathrm{ml}$ MatriSperse cell recovery solution (Becton Dickinson) on ice for $2 \mathrm{~h}$ to allow depolymerisation. The organoid suspension was centrifuged at $150 \mathrm{~g}$ for $5 \mathrm{~min}$ and trypsinised in PBS containing 0.02\% EDTA and $1 \mathrm{mg} / \mathrm{ml}$ trypsin. The single cell suspension was collected at $150 \mathrm{~g}$ for $5 \mathrm{~min}$ and resuspended in DMEM:F12 containing 10\% FCS. The number of cells in each well was counted using a haemocytometer in $50 \%$ (v/v) trypan blue (Sigma).

\section{Purification of primary breast epithelial and myoepithelial cells}

Purification of breast epithelial and myoepithelial cells was performed according to methods described previously
(Gomm et al. 1995). Essentially, enriched breast organoids obtained as described above were trypsinised with 0.05\% high grade trypsin (Hyclone Europe Ltd, Northumberland, UK) in PBS containing $0.02 \%$ EDTA and $0.4 \mathrm{mg} / \mathrm{ml}$ DNase 1 (Sigma). The blood cells in the cell suspension were eliminated by three rounds of depletion using anti-common acute lymphoblastic leukaemia antigen (Sera-Lab, Loughborough, UK) conjugated to $4.5 \mu \mathrm{m}$ Dynabeads (Dynal) according to the manufacturer's protocol. Dynabead-conjugated rat monoclonal anti-epithelial membrane antigen was then used to positively select for epithelial and myoepithelial cells as described (Gomm et al. 1995). The purified epithelial cells were cultured using BCM with FCS and the myoepithelial cells in mammary epithelial growth medium (MEGM) (Clonetics, Wokingham, UK) (Gomm et al. 1995).

\section{Isolation of primary breast fibroblasts and FGF7 release assay}

Human breast fibroblasts obtained from the supernatants of the sedimentation step during breast cell purification and organoid isolation were cultured in DMEM with 10\% FCS, $2 \mathrm{mM}$ glutamine, $100 \mathrm{U} / \mathrm{ml}$ penicillin and $0.1 \mathrm{mg} /$ $\mathrm{ml}$ streptomycin, to select for stromal cells. To assess the effects of different growth factors and ligands on the production of FGF7, the purified breast fibroblasts were incubated with different cytokines and ligands. The amount of FGF7 produced by the fibroblasts in the CM was measured using the human KGF Quantikine Kit (R\&D Systems) according to the manufacturer's protocol. The human KGF Quantikine Kit was an ELISA-based quantification assay, and the absorbance was measured at a wavelength of $450 \mathrm{~nm}$ within $30 \mathrm{~min}$ using a 550 Plate Reader (Bio-Rad). FGF1, FGF2 and FGF8 and IL-1 $\beta$ were purchased from R\&D Systems. $\beta$-Oestradiol and 4-hydroxy tamoxifen were obtained from Sigma.

\section{Culture of breast cell lines and measurement of cell proliferation}

In studies involving breast cancer cell lines, the following cells lines were used MCF7, T47D, MDA-MB-231, ZR75.1 (breast carcinoma), HBL100 (breast cancer cell line of myoepithelial origin), HMT3552, HBrSV1·6.1 (normal immortalised breast epithelial cell lines) and NIH3T3 (mouse fibroblast cell line that does not express FGFR2-IIIb). Cells were cultured with 10\% newborn calf serum, to approximately $80 \%$ confluence with medium changes every other day before being passaged into culture plates for the growth assays. Trypsinised cells were seeded into triplicate wells at a concentration of $5 \times 10^{4}$ cells per well in 24-well tissue culture plates and cultured in DMEM:F12 containing 1\% serum and antibiotics (100 $\mathrm{U} / \mathrm{ml}$ penicillin, $100 \mu \mathrm{g} / \mathrm{ml}$ streptomycin), in the presence or absence of $20 \mathrm{ng} / \mathrm{ml}$ recombinant FGF7 for up to 5 days. The method for the methylene blue assay has been described previously (Harris et al. 1999). At each time 
point the cells in the wells were stained with $50 \%(\mathrm{v} / \mathrm{v})$ ethanol containing $0.5 \%$ methylene blue $(\mathrm{v} / \mathrm{v})$ for $2 \mathrm{~h}$, washed thoroughly with water and left to dry inverted overnight. The stain in each well was dissolved with $0.5 \mathrm{ml} \mathrm{1 \%}$ lauryl sarkosyl (v/v) (Merck, Hoddesdon, Herts, UK) in PBS for $1 \mathrm{~h}$, and the resulting solution was transferred to three wells of a 96-well plate and absorbance at $650 \mathrm{~nm}$ was determined using a microplate reader (Bio-Rad).

\section{Results}

\section{Characterisation of antibodies to FGF7}

We first carried out experiments to characterise a number of FGF7 antibodies in order to identify an appropriate antibody for subsequent immunohistochemical studies. To determine the specificity of the FGF7 antibodies, we performed Western blot analysis with recombinant human FGF7 and FGF10. The results showed that the FGF7 antibodies N-14 and both R\&D Systems' monoclonal antibodies cross-react with FGF10 or other higher molecular weight species, while the antibodies $\mathrm{H}-73$ and C-19 showed no significant cross-reactivity (Fig. 1A). The result also demonstrated that the control FGF10 antibody recognised only the recombinant FGF10 but not FGF7.

The epitopes for most FGF7 antibodies are located near the C-terminus, which also contains the heparan sulphate proteoglycan (HSPG)-binding site. In order to determine if the antibodies C-19 and H-73 could identify HSPGbound FGF7 or whether HSPG blocks the binding of the FGF7 antibody, the FGF7 antibodies were used in ELISA assays to detect recombinant FGF7 in the presence of heparin (low and high molecular weights) or heparan sulphate. As control, the assay was also performed in the absence of FGF7 antibodies. The data show in Fig. 1B that heparin or heparan sulphate could cause an 85-100\% reduction in FGF7 binding by the $\mathrm{C}-19$ antibody using this assay. By contrast, only low levels of inhibition of binding by heparin (10-25\%) were observed with the $\mathrm{H}-73$ antibody and the inhibition was minimal compared with C-19. The lower level of inhibition exhibited by this antibody suggests that it is likely to give more reliable results than the C-19 antibody when applied to immunohistochemical studies.

\section{FGF7 localisation by immunohistochemstry using the H-73 antibody}

We next undertook an immunohistochemical survey of a range of archival breast tissues using the $\mathrm{H}-73$ antibody. Normal nipple samples consisting of skin and large ducts were used as positive controls for immunohistochemical staining. FGF7 staining was detected in the epidermal layers and epithelium of the large ducts, but not in the stroma (Fig. 2A). In normal breast tissues, there is minimal stromal staining, but staining is observed in the ductal epithelium (Fig. 2A). However, in two of ten normal breast sections, the FGF7 antibody stained predominantly in the myoepithelium, with virtually no staining of the luminal layer (Fig. 2B and C).

Immunostaining was also carried out in a range of benign tumours of different histopathological subtypes. In the phyllodes (Fig. 2D), duct ectasia (Fig. 2E) and hamartoma specimens (Fig. 2F), FGF7 staining was observed largely in both epithelial and myoepithelial cells of the ducts and stromal staining was minimal (Fig. 2D-F). Similarly, in the fibrocystic (Fig. 2G) and epithelial hyperplasia specimens (Fig. 2H), FGF7 staining was generally observed in both cell types. However, predominant myoepithelial staining was observed in a fraction of the fibrocystic (two of ten) (Fig. 2I) and the epithelial hyperplasia (one of two) (Fig. 2J) samples. Again, stromal staining was minimal in these benign tumours.

For the malignant specimens, samples stained were again divided into histopathological subtypes. Figure $2 \mathrm{~K}$ shows FGF7 staining for DCIS, and the result showed staining in the malignant epithelium but not in the stroma. This pattern was similar to that seen in the invasive tumours, regardless of grade. An example of epithelial staining in invasive tumours (grade 2 cancers) is shown in Fig. 2L. Although, similar to DCIS, epithelial staining was observed in two of five LCIS samples (Fig. 2M), one of the five samples showed diffuse FGF7 staining in the stromal compartment but no epithelial staining (Fig. $2 \mathrm{~N}$ ). The rest of the LCIS samples (two of five) showed both epithelial and stromal FGF7 staining. Such a stromal staining pattern in three of five LCIS samples was not observed for any other histological subtype. For negative controls, adjacent sections of specimens from each histological type were stained with a non-immune IgG and all FGF7 staining was unaffected by the addition of excess FGF1, FGF2 or FGF10. Figure $2 \mathrm{O}$ and $\mathrm{P}$ show a normal nipple sample stained with a non-immune IgG and the H-73 FGF7 antibody respectively. In normal breast samples, FGF7 staining was observed predominantly in the epithelial cells (Fig. 2P) and there was a lack of staining with the non-immune IgG (Fig. 2O). Incubating the primary antibody with excess FGF10 and heparin has no effect on FGF7 staining of normal breast samples (Fig. 2Q), while incubation with excess FGF7 and heparin completely abolished the staining (Fig. 2R).

A study of FGF7 immunostaining on frozen sections of 21 breast carcinomas and six benign breast tissues was also carried out. Again, the epithelial cells of carcinomas stained positively in 15 of 17 cases, but there was also evidence of stromal staining in three samples, all of which were invasive ductal carcinomas. In non-neoplastic samples, five of six samples were positive, again in epithelial cells (data not shown), while no stromal staining was observed. To compare the expression of FGF10 with FGF7, we examined frozen tissue samples, consisting of 
A)

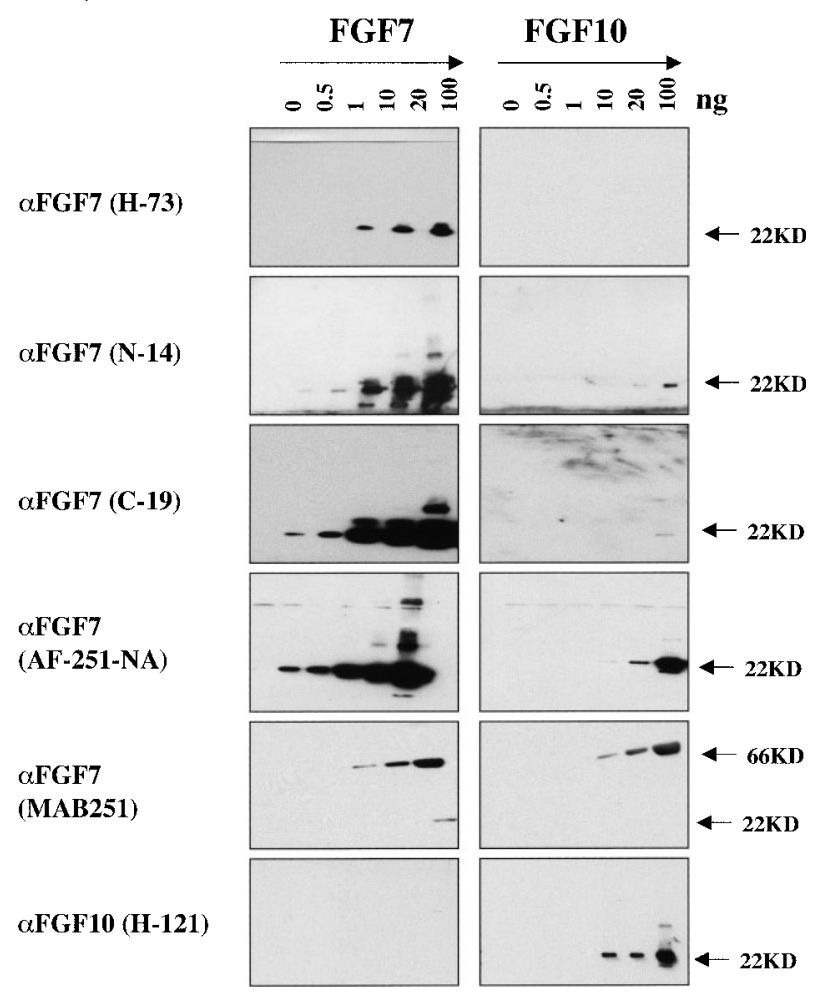

B)
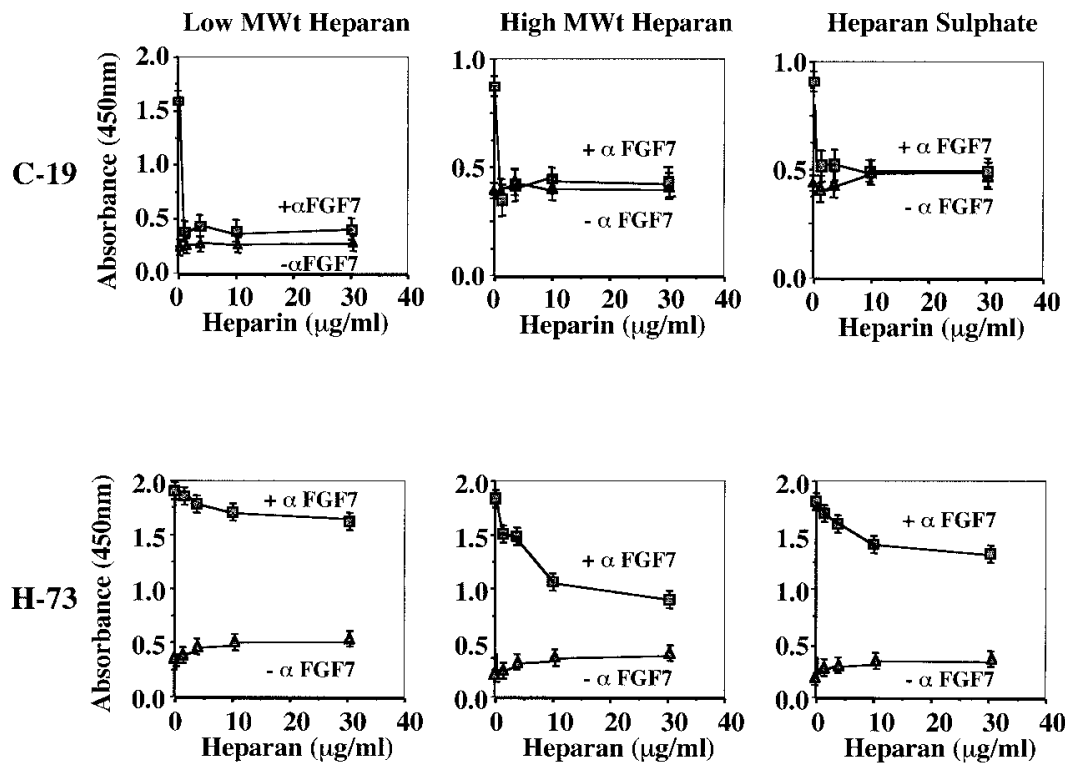

Figure 1 Western blot analysis (A) and ELISA (B) of recombinant FGF7 and FGF10 protein using different FGF7 and FGF10 antibodies. Different amounts of recombinant FGF7 or FGF10 protein $(0,0 \cdot 5,1,10,20$ or $100 \mathrm{ng})$ were resolved on a 12\% SDS-PAGE gel and Western blotted with different FGF7 and FGF10 antibodies. The H-73 and C-19 anti-FGF7 were used to detect $1 \mu \mathrm{g} / \mathrm{ml}$ in an ELISA in the presence of increasing concentrations $(0,1,3,10$ or $30 \mu \mathrm{g} / \mathrm{ml})$ of low or high molecular weight heparin or heparin sulphate (+ $\alpha$ FGF7). The reference controls $(-\alpha$ FGF7) were performed in the absence of anti-FGF7 antibody. Each point represents the result from triplicate experiments; error bars represent S.E.M. 
normal breast tissue obtained from reduction mammoplasty (Fig. 3A), fibroadenomas (Fig. 3B), DCIS (Fig. 3C) and invasive ductal carcinomas (Fig. 3D). The staining in these all tissue sections revealed predominately epithelial staining, with very little stromal FGF10 staining. The staining with the control goat IgG antibodies was again negative for normal breast tissue (Fig. 3E), fibroadenomas (Fig. 3F), DCIS (Fig. 3G) and invasive ductal carcinomas (Fig. $3 \mathrm{H})$.

\section{Immunolocalisation of FGFR2 in the normal and malignant breast}

In order to confirm the cellular localisation of the receptor for FGF7, a specific FGFR2 antibody (C-19) was used on paraffin-embedded samples of breast tissue. Figure 3I-K shows typical localisation in normal, benign and malignant specimens. FGFR2 staining was associated with the cytoplasm and membrane of both epithelial and myoepithelial cells in four normal breast samples (Fig. 3I) and ten benign breast samples (Fig. 3J). Similarly in eight cancer specimens, staining was observed in the cytoplasm and membrane of the malignant epithelial cells (Fig. 3K). FGFR2 staining was never observed in stromal cells in all breast tissue samples studied, and there was no significant difference in the degree and distribution of staining between normal and malignant specimens. In the controls, staining was abolished by pre-incubation with excess immunising peptide. Parallel sections of normal, benign and cancer specimens were tested with non-immune $\operatorname{IgG}$, but no staining was detected. A typical example of staining with non-immune $\operatorname{IgG}$ is shown in Fig. 3L. This FGFR2 staining is specific for FGFR2-IIIb as the antibody used (C-17) does not recognise the FGFR2-IIIc isoform and the staining can be blocked with excess immunising peptide (Fig. 3M and N).

In summary, the immunohistochemical studies indicated that FGF7 and its receptor (FGFR2) were localised predominantly to the epithelial and myoepithelial cells in both normal and malignant breast tissue, and this pattern of FGF7 and receptor staining is consistent with the notion that the epithelial and myoepithelial cells are the cellular targets of FGF7, which originates from stromal fibroblasts.

\section{Mitogenic effects of breast fibroblast-CM and FGF7 on normal breast epithelial cells}

We next examined the ability of fibroblast-CM to stimulate the proliferation of purified breast epithelial cells in vitro. Figure $4 \mathrm{~A}$ demonstrates that fibroblast-CM, even when added to growth medium (BCM) containing FCS and growth factors (e.g. EGF, FGFs and cytokines) at optimal concentrations, still resulted in additional proliferation. This effect was dose-dependent at the dose ranges tested (Fig. 4A) and the proliferative activity of the CMs was almost completely neutralised by an antibody to FGF7 in each of the three different patients' samples tested (Fig. $4 \mathrm{~B}$ ), suggesting that FGF7 is the mitogenic component present in the breast fibroblast-CM responsible for promoting epithelial growth. We were unable to carry out a similar experiment with the purified primary myoepithelial cells since the FCS present in the fibroblast-CM would have inhibited myoepithelial cell growth (Gomm et al. 1995). We also tested the ability of the breast fibroblast-CM to promote the growth of two normal epithelial (HMT3552 and HBrSV1·6·1) and a myoepithelial (HBL100) cell line. The result showed that the CM promoted the growth of all three cell lines (Fig. 4C). Moreover, the growth induced by fibroblastic CM could be blocked effectively by the neutralising anti-FGF7 antibody (MAB251) in the epithelial cell lines, HMT3552 and HBrSV1.6.1, but not in the myoepithelial line HBL100 (Fig. 4C). Specific neutralising antibodies against FGF1 (AB-32-NA) and FGF2 (AB-33-NA) were also used to block the mitogenic effects of the CM but no growth inhibitory effect was observed This indicates that the neutralising effects of the anti-FGF7 antibody (MAB251) is specific.

We then studied the effect of FGF7 on the proliferation of purified primary epithelial and myoepithelial cells (Gomm et al. 1995). Figure 5A shows the effect on the proliferation of epithelial cells of the addition of $10 \mathrm{ng} / \mathrm{ml}$ FGF7 in conjunction with varying concentrations of FCS. As previously described (Jackson et al. 1997), primary luminal epithelial cells show a decrease in cell number in low serum conditions compared with cells cultured in 10\% FCS. This reduction in cells induced by serum starvation is partly abrogated by the addition of FGF7. In combination with either 1 or 5\% FCS, FGF7 stimulated epithelial cell growth $(P<0 \cdot 001$; Student's $t$-test $)$. We next examined the effects of FGF7, FGF1 and FGF2 on myoepithelial cell proliferation. Myoepithelial cells do not survive in FCS-supplemented medium (Jackson et al. 1997) and thus it was impossible to compare them directly with luminal epithelial cells at similar FCS concentrations. However, Fig. 5B demonstrates a measurable increase in the rate of myoepithelial cell proliferation with FGF7 $(P<0 \cdot 01)$ over control cells cultured with only MEGM. Interestingly, both FGF1 and FGF2 did not induce proliferation, confirming our previous observations.

\section{The effect of FGF7 on proliferation of normal and malignant breast cell lines}

Figure 6 shows the effect of 5 and $20 \mathrm{ng} / \mathrm{ml}$ FGF7 compared with controls in a subset of normal and malignant breast cell lines of epithelial and myoepithelial origins. All the cell lines, including HBrSV1·6·1 (Fig. 6A), T47D (Fig. 6B), HMT3552 (Fig. 6C), MDA-MB-231 (Fig. 6D), HBL100 (Fig. 6E), MCF7 (Fig. 6F) and ZR75.1 (Fig. $6 \mathrm{G}$ ), showed significant but small changes in cell number, which varied between the different cell lines after 10 days. 


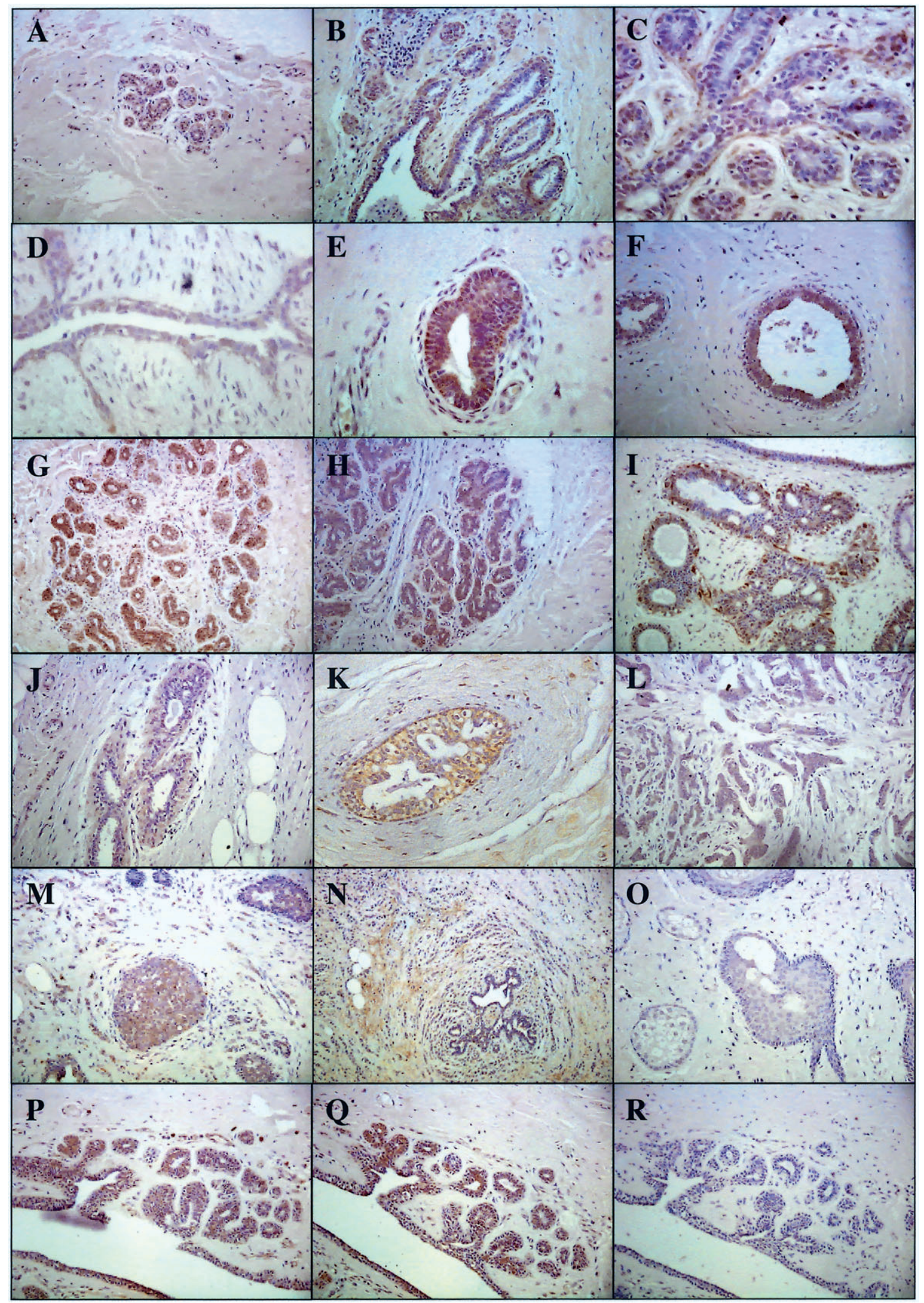


As expected, the control mouse NIH3T3 fibroblast cell line (Fig. 6H), which does not express FGFR2-IIIb, showed negligible changes in cell number in response to FGF7.

\section{The effect of FGF7 on breast organoids}

The effect of FGF7 as a morphogen of breast organoids prepared from reduction mammoplasty tissue (seven normal individual samples) was examined by observing the gross appearance of organoids after embedding in Matrigel basement matrix. The organoids were observed daily by phase contrast microscopy for up to 3 weeks. Treatment with culture medium (BCM plus 10\% FCS) induced a significant but low level of amorphous growth (Fig. 7B) compared with similar untreated cultures (Fig. 7A). This low level of growth could be abolished by treatment with a neutralising antibody against FGF7 (Fig. 7E), but not with neutralising antibodies against FGF1 (Fig. 7C) or FGF2 (Fig. 7D). FGF7-treated organoids also showed more extensive outgrowth (Fig. 7H) compared with controls cultured with FGF1 (Fig. 7F) or FGF2 (Fig. 7G). In order to quantify the effect of FGF7 on breast organoids in the organ culture model, the organoids were retrieved from the Matrigel and trypsinised into single cell suspensions. Figure 7I and G show that there were more cells present at the end of the culture period in wells containing FGF7 than in control wells $(P=0 \cdot 042)$ (Student's $t$-test).

\section{Characterisation of FGF7 release from normal breast fibroblasts}

In previous sections, we showed that FGF7 is produced by the breast fibroblasts and is both a mitogen and morphogen for breast epithelial and myoepithelial cells. We next sought to determine the factors that regulate FGF7 release from breast fibroblasts and carried out experiments to examine the effects of various cytokines, including IL-1 $\beta$, FGF1, FGF2 and FGF8, as well as oestrogen receptor ligands, including oestradiol and tamoxifen, on FGF7 release from breast fibroblasts. IL- $1 \beta$ was included in this study because previous nuclear run-on and promoter studies on the FGF7 gene indicated that IL-1 can stimulate FGF7 gene transcription (Chedid et al. 1994, Finch et al. 1995b). Moreover, previous studies have demonstrated that IL-1 $\beta$ can induce stromal cells to secrete FGF7 in cornea, skin and endometrium (Chedid et al. 1994, Finch et al. 1995b, Li \& Tseng 1997, Weng et al. 1997, Li \& Rinehart 1998). These findings suggest that IL-1 $\beta$ could also have a role in inducing FGF7 production in breast stromal cells. To this end, purified stromal cells obtained from normal breast biopsies were cultured in the absence or presence of different concentrations of stimuli and the FGF7 released into the culture media was detected by ELISA. Of these stimuli, only IL- $1 \beta$ gave reproducibly positive results and was shown to induce FGF7 release from breast fibroblasts (Fig. 8A). To further confirm this observation, we therefore decided to investigate the effect of IL-1 $\beta$ on fibroblast FGF7 release at concentrations from 0.001 to $10 \mathrm{ng} / \mathrm{ml}$ (Fig. 8B). Significant stimulation of FGF7 release was observed at IL- $1 \beta$ concentrations greater than $0.01 \mathrm{ng} / \mathrm{ml}$ and the level of FGF7 release increased with concentrations of IL- $1 \beta$ until a plateau was reached at $1-10 \mathrm{ng} / \mathrm{ml}$. This finding not only shows that IL-1 $\beta$ could be an important modulator of FGF7 expression and thus breast cell growth, but also further confirms that the stromal fibroblasts are the origin of FGF7 in the breast.

\section{Discussion}

Our results support an important role for FGF7 in human breast epithelial proliferation. They also show that breast stromal fibroblasts are the origin of FGF7 and that FGF7 release leads to its localisation in and around the cells of normal breast ducts and lobules. Our studies suggest that stromally released FGF7 is biologically active, since CM from stromal cells promoted luminal epithelial and myoepithelial cell proliferation in vitro and this could be abrogated by a neutralising antibody to FGF7. Consistent with this, fibroblast feeder layers have been previously shown to facilitate the culture of human and rat mammary epithelial cells (Guo et al. 1996, Mann \& Borgen 1998) and other studies have demonstrated the existence of epithelial cell growth factors in the CM from breast fibroblast cultures (Ulich et al. 1994, Wilson et al. 1994, 1999, Bansal et al. 1997, Jacquemier et al. 1998). Furthering these observations, we show that FGF7 is the mitogenic and morphogenic component in the CM from breast fibroblast cultures.

The present findings further support previous PCRbased data which showed FGF7 mRNA localises in the stromal compartment of the breast (Bansal et al. 1997). More importantly, our results confirm that FGFR2-IIIb, the receptor for FGF7, is localised in breast epithelial and myoepithelial cells. Interestingly, we found no evidence for the existence of the receptor for FGF7 in stromal cells, indicating that the cellular targets of FGF7 in the breast are

\footnotetext{
Figure 2 Immunostaining of normal and malignant human breast tissues using the FGF7 antibody. Representative photomicrographs of immunohistochemical staining of breast sections using the H-73 FGF7 antibody and DAB as substrate. All micrographs were at $\times 200$ magnification (except $\mathrm{C}$ at $\times 400$ ). (A-C) Normal breast; (D) phyllodes; (E) duct ectasia; (F) hamartoma; (G and I) fibrocystic hyperplasia; ( $\mathrm{H}$ and J) epithelial hyperplasia; (K) DCIS; (L) invasive carcinoma 2; (M and N) LCIS; $(\mathrm{O})$ normal nipple stained with non-immune IgG; $(\mathrm{P})$ normal nipple with H-73 FGF7; (Q) normal nipple with H-73 FGF7 and excess FGF10 and heparin; (R) normal nipple with H-73 FGF7 and excess FGF7 and heparin.
} 


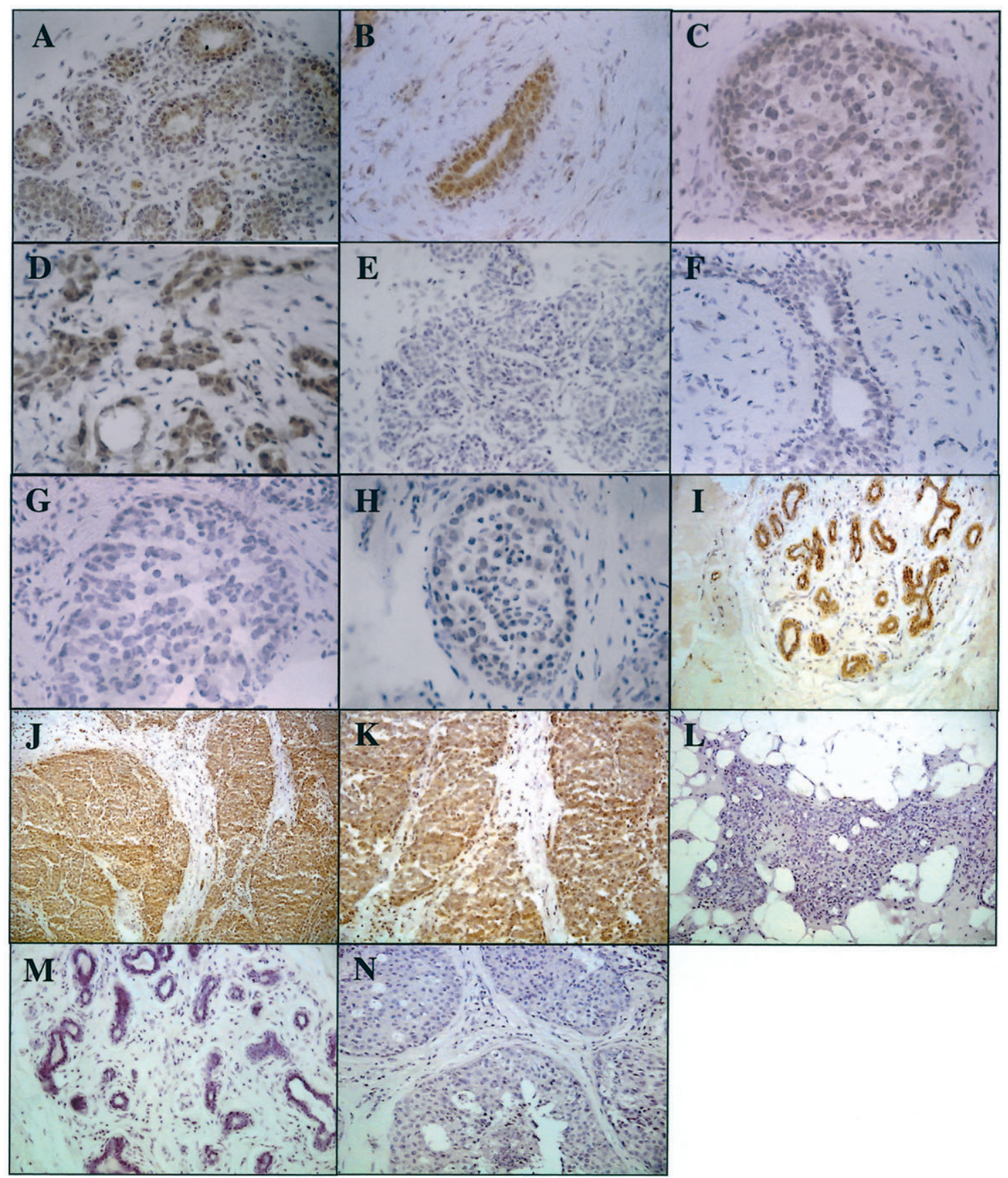

Figure 3 Immunostaining of normal and malignant human breast tissues using the FGF10 and FGFR2 antibodies.

Representative photomicrographs of immunohistochemical staining of breast sections using DAB as substrate at $\times 200$ magnification. Breast sections of (A) normal breast from reduction mammoplasty, (B) fibroadenomas, (C) DCIS and (D) invasive ductal carcinomas were stained using the H-121 FGF10 antibody. Sections of (E) normal breast from reduction mammoplasty, (F) fibroadenomas, (G) DCIS and (H) invasive ductal carcinomas were also stained with a non-immune IgG. The FGFR2 (C-19) antibody was used to stain sections of (I) normal, (J) benign and (K) malignant breasts. (L) An invasive carcinoma section stained with a non-immune IgG. The FGFR2 staining was blocked using excess immunising peptide, in both $(\mathrm{M})$ normal breast and $(\mathrm{N})$ infiltrating ductal carcinoma. 

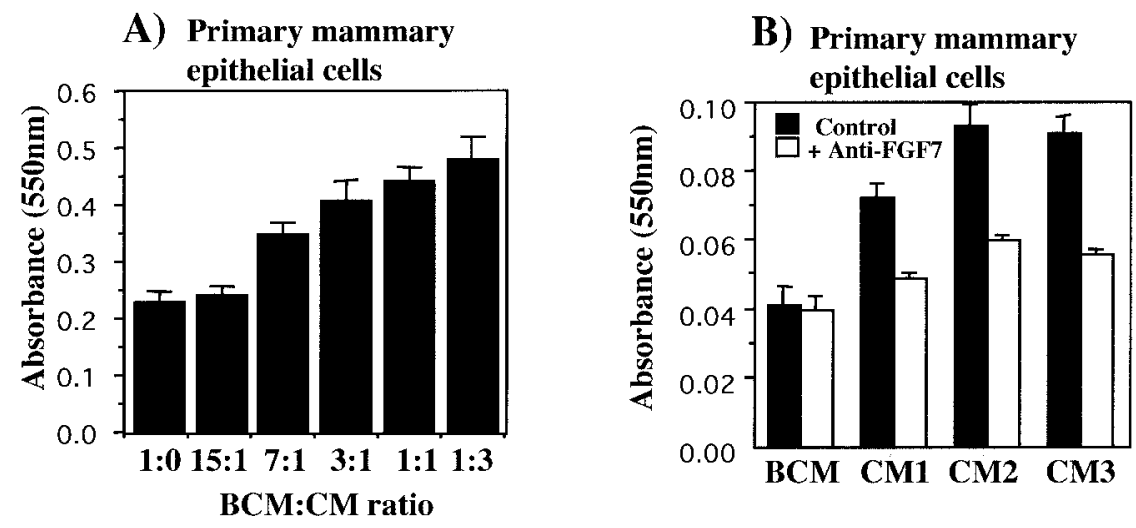

\section{C)}
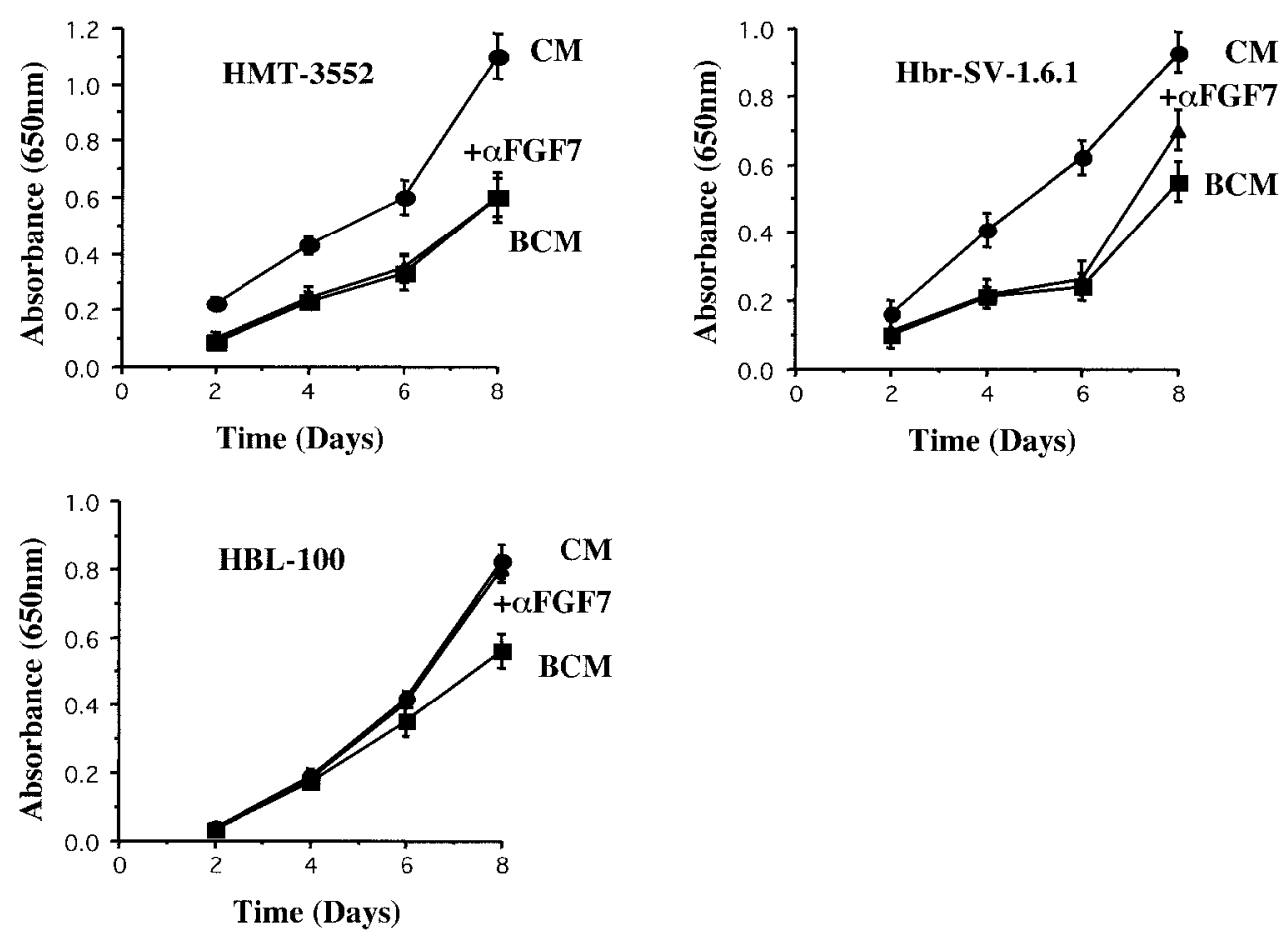

Figure 4 Effect of breast fibroblast-CM on epithelial and myoepithelial cell proliferation. The effect of breast fibroblast-CM on cell growth was determined by the $\mathrm{MTT}$ assay in (A) purified primary breast epithelial cells which were cultured in different ratios of $\mathrm{BCM}: \mathrm{CM}(1: 0,15 ; 1,7: 1,3: 1,1: 1,1: 3)$. After 10 days of culture the cells were harvested and growth was estimated. (B) Purified primary breast epithelial cells which were cultured with either $\mathrm{BCM}$ or $\mathrm{CM}$ from one of the three independent breast fibroblast cultures in the absence or presence of a neutralising FGF7 antibody. (C) The normal breast epithelial cell lines HMT3552 and $\mathrm{HBrSV} 1 \cdot 6 \cdot 1$ and normal breast myoepithelial cell line HBL100 were incubated with either BCM or CM in the absence $(\mathrm{CM})$ or presence of a neutralising FGF7 antibody ( $\alpha$ FGF7). Each point represents the mean \pm S.E.M. of $n \geq 3$.

epithelial cells and not fibroblasts. Immunostaining using the FGF7-specific H-73 antibody revealed epithelial and myoepithelial staining. Since FGF7 caused proliferation of both epithelial and myoepithelial cells, it is possible that the localisation of FGF7 to the ductal epithelium rep- resents staining of FGFR2-IIIb-bound FGF7. This is also the conclusion reached by Jacquemier et al. (1998) in their study on FGF7 expression in human breast carcinomas, which identified FGF7 staining in malignant epithelium as well as stromal compartments. However, our data clearly 

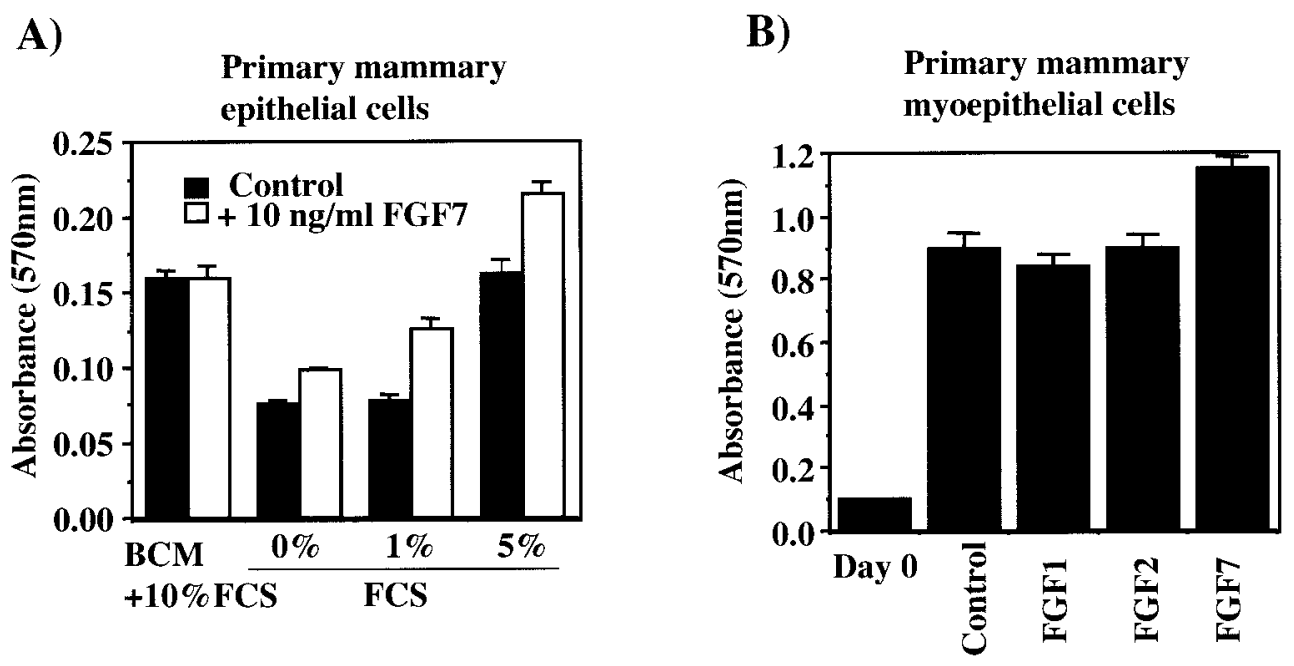

Figure 5 Effect of FGF7 on the primary epithelial and myoepithelial cell proliferation. (A) Purified primary breast epithelial cells cultured in BCM with $10 \%$ FCS or in 0,1 or $5 \%$ FCS after serum starvation were incubated with or without $10 \mathrm{ng} / \mathrm{ml}$ FGF7. After 10 days of culture, the cells were harvested and growth was estimated using MTT assays. (B) Purified primary breast myoepithelial cells (day 0) cultured in BCM alone (control) or BCM with FGF1, FGF2 or FGF7 for 10 days were harvested and analysed using MTT assays. Each point represents the mean \pm S.E.M. of $n \geq 3$.

demonstrate that the fibroblasts in the stroma displayed no immunoreactivity towards the FGF7-specific receptor FGFR2-IIIb antibody, which strongly suggests that FGF7 is not binding to stromal fibroblasts via FGFR2-IIIb. It is also notable that the antibody used in this particular study (Jacquemier et al. 1998) was the monoclonal antibody (MAB251) which we have found to cross-react strongly with an unidentified FGF10 recombinant protein of $66 \mathrm{kDa}$.

The presence of receptor-bound FGF7 may also provide an explanation for the predominantly myoepithelial staining observed in several normal and benign samples. Consistent with this idea, we have previously found that the level of FGFR2-IIIb expression is higher in separated pure populations of human breast myoepithelial when compared with epithelial cells (Johnston et al. 1995). The apparent stromal staining observed in LCIS is interesting, but a complete explanation as to why FGF7 is detected in only a proportion of LCIS samples remains elusive.

Our previous studies have only addressed FGFR2 staining in breast cell lines using immunofluorescence (Johnston et al. 1995). In order to determine the distribution of FGFR2-IIIb in the breast, an immunohistochemical study was performed on normal and malignant breast sections. The pattern of FGFR2 staining is consistent with its previously published mRNA distribution (Luqmani et al. 1996, Bansal et al. 1997), with FGFR2 observed in both epithelial and myoepithelial cell layers. It is notable that the myoepithelial cell layer does not stain more intensely than the luminal layer, considering that the myoepithelial cells express higher levels of the receptor (Bansal et al. 1997). The distribution of staining was homogeneous, predominantly membranous and cytoplasmic, and was identical to that seen in COS-7 cells transfected with full-length FGFR 2 and in breast cell lines (Johnston et al. 1995). Also, FGFR2 was localised to malignant epithelial cells with a cellular distribution similar to the membranous and cytoplasmic staining observed in the normal sections. These data agree with our previous reports, which demonstrated FGFR2 mRNA in cancer specimens and in malignant epithelial cells (Luqmani et al. 1996, Bansal et al. 1997).

However, it should be noted that the previous mRNA studies distinguished between IIIb and IIIc forms of the receptor whereas the antibody used does not differentiate between these isoforms. It is surprising that no FGFR2 staining was observed, in either normal or malignant specimens in the stroma, considering that the IIIc isoform is often expressed by mesenchymal cells to complement expression of the IIIb isoform by epithelial cells (Pekonen et al. 1993, Savagner et al. 1994).

Although the majority of published data indicate that FGF7 is produced by fibroblasts and thus the stroma is the most likely site of FGF7 production in the breast, some data suggest that lymphocytes are a possible source, since $\mathrm{T}$ cells have been shown to produce FGF7 in inflammatory bowel disease (Finch et al. 1995a) and FGF7 synthesis has also been localised to intraepithelial $\gamma \delta \mathrm{T}$ cells in the skin (Boismenu \& Havran 1994). To exclude this possibility, we used an immortalised breast fibroblast cell line and 

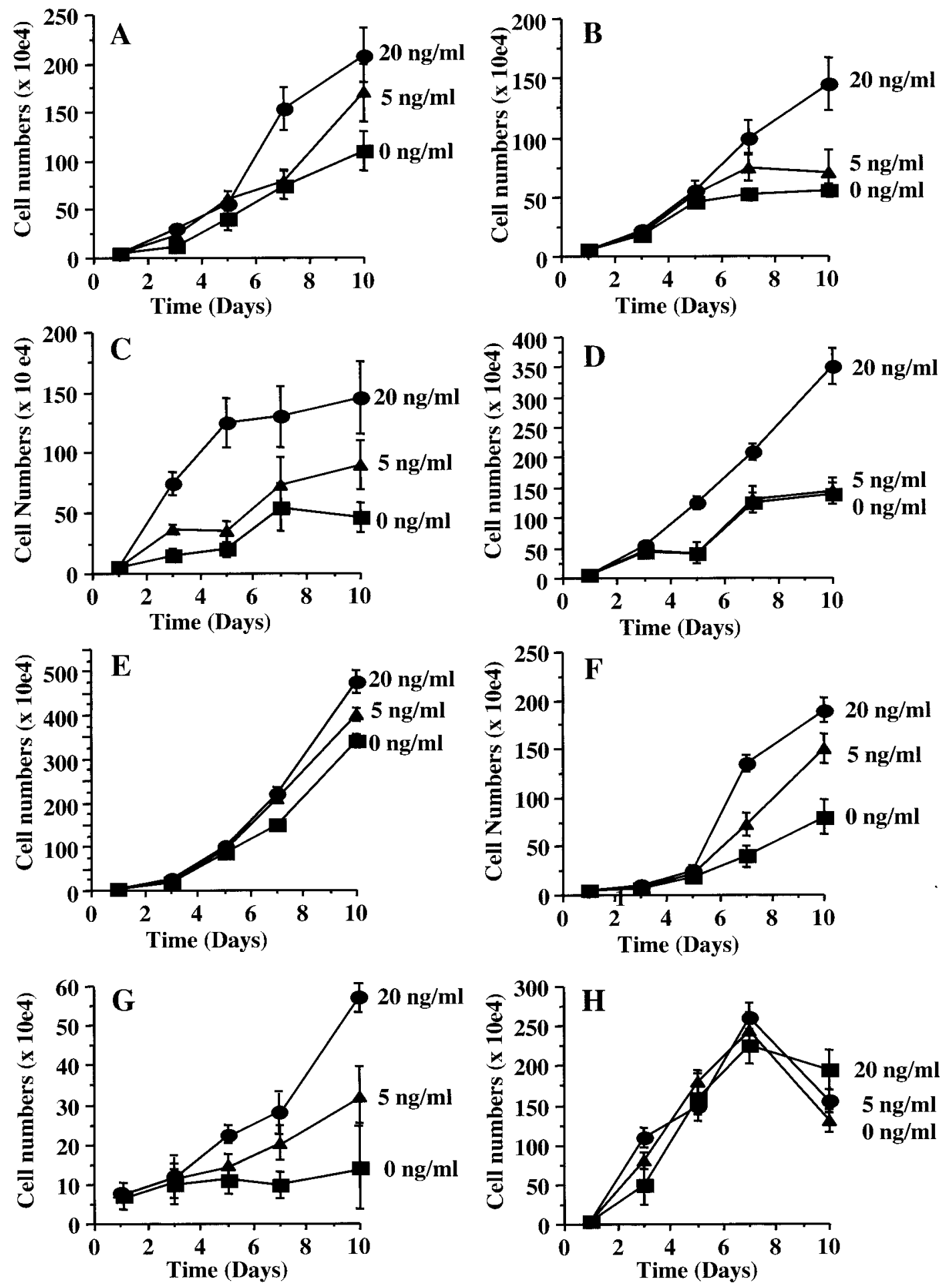

Figure 6 Effect of FGF7 on the proliferation of normal and malignant breast cancer cell lines. Normal and malignant human breast cell lines: HBrSV1·6.1 (A), T47D (B), HMT3552 (C), MDA-MB-231 (D), HBL100 (E), MCF7 (F) and ZR75.1 (G) were cultured in BCM in the presence of 0,5 or $20 \mathrm{ng} / \mathrm{ml} \mathrm{FGF7.} \mathrm{The} \mathrm{murine} \mathrm{fibroblast} \mathrm{NIH3T3} \mathrm{cells}$ were included as a control $(\mathrm{H})$. The numbers of cells were counted and recorded at day 1, 3, 5, 7 and 10. Each point represents the mean \pm S.E.M. of $n \geq 3$. 


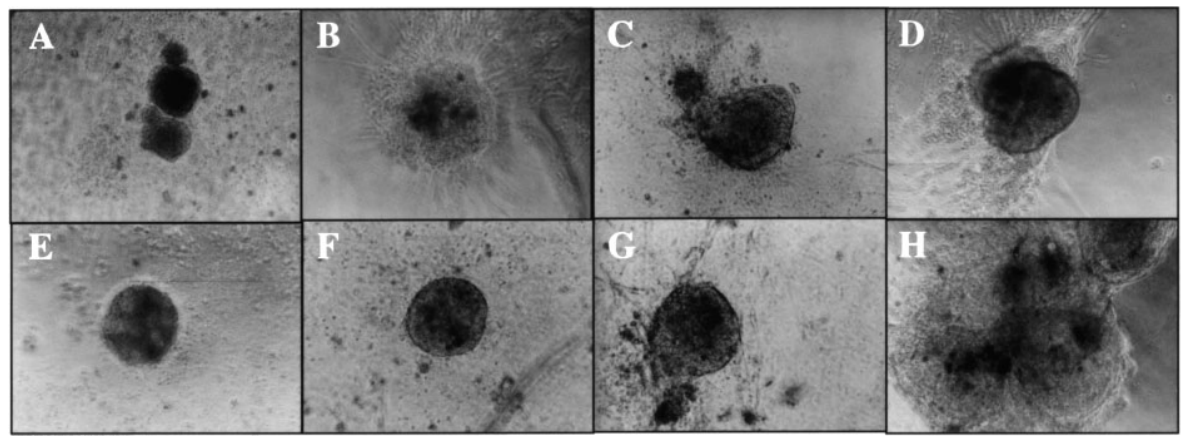

I)

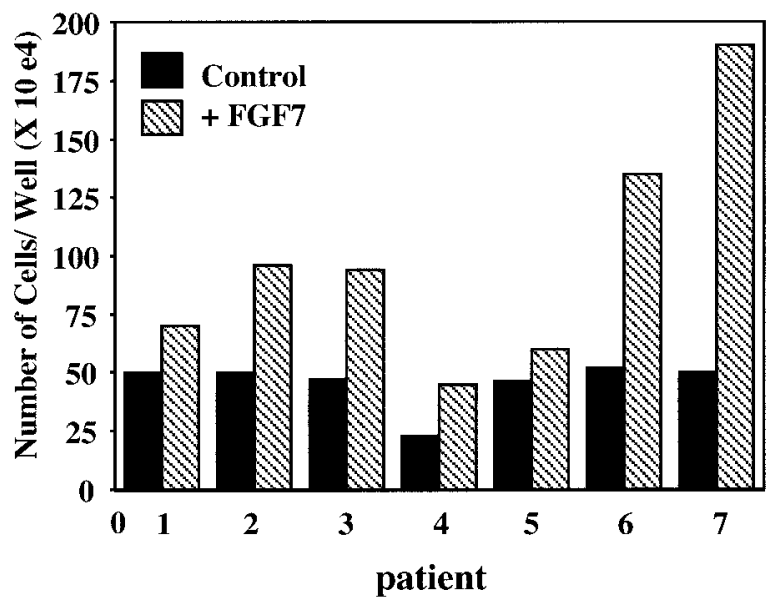

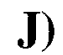

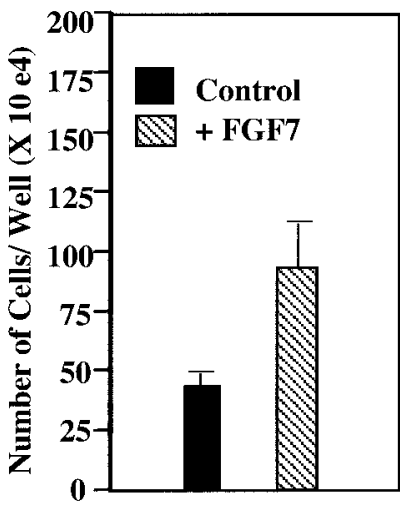

Figure 7 Effect of FGF7 on the morphology and growth of breast organoids. Micrographs of Matrigel-embedded breast organoids before treatment (A) and after treatment with BCM only (B) or BCM with a neutralising anti-FGF1 (C), anti-FGF2 (D) or anti-FGF7 (E), or BCM with FGF1 (F), FGF2 (G) or FGF7(H). (I) Seven independent Matrigel-embedded breast organoid samples were incubated with $\mathrm{BCM}$ in the presence or absence of FGF7. After 10 days, the organoids were trypsinised and cell numbers counted. (J) Histogram showing the mean number of cells \pm S.E.M. in seven samples treated with $20 \mathrm{ng} / \mathrm{ml}$ and untreated control wells.

found that the FGF7 production rate from this line was the highest we have observed from any stromal cell preparation.

We attempted to seek a role for FGF7 as a mediator of hormonal action. FGF7 has been shown to mediate androgen action in androgen-dependent epithelium such as prostate and seminal vesicles (Yan et al. 1993, Fukabori et al. 1994, Peehl \& Rubin 1995, Peehl et al. 1996, Sugimura et al. 1996). There is also some evidence to suggest a progesterone-dependent expression of FGF7 mRNA in stromal cells of the primate endometrium (Koji et al. 1994). However, Pedchenko \& Imagawa (1998) showed that progesterone and prolactin synergised with FGF7 in stimulating the proliferation of ductal mammary epithelium through inducing the expression of the FGFR
mRNA in the mammary epithelial cells. Several reports have suggested that FGF7 may be oestrogen regulated (Zhang et al. 1998a,b). Two half-palindromic oestrogenresponse motifs are present in the FGF7 promoter suggesting a role for oestrogen in FGF7 regulation (Cardiff \& Wellings 1999). At odds with these reports, the present study failed to demonstrate a significant role for oestrogen in FGF7 release in purified breast fibroblasts. Pedchenko \& Imagawa (2000) showed that oestrogen can stimulate mammary expression of FGF7 mRNA and protein in vivo. However, this effect could be indirect and perhaps mediated by a local pathway, as cell types other than fibroblasts exist in this experimental system.

Nevertheless, our study indicates that IL- $1 \beta$ is a potent cytokine involved in FGF7 release; thus, deregulation of 

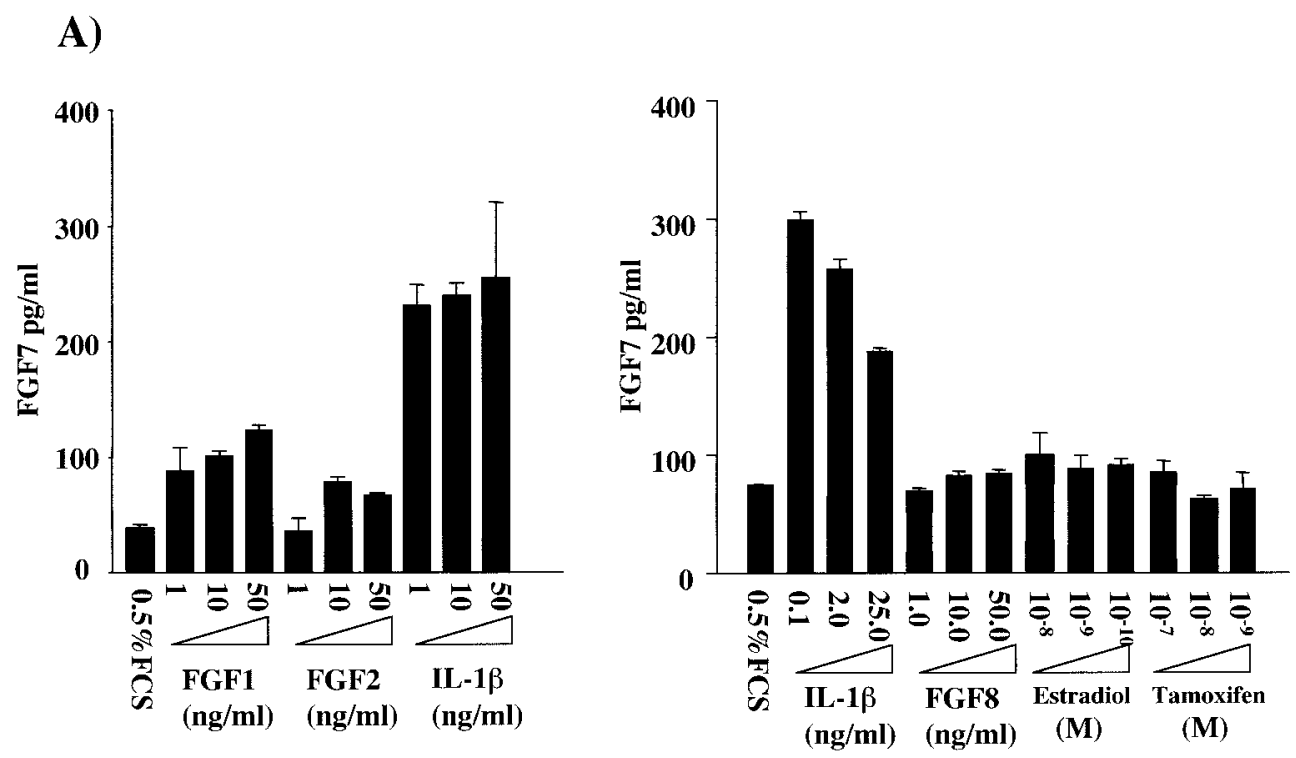

B)

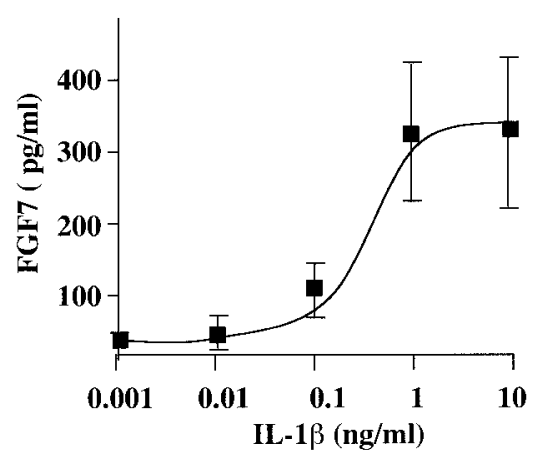

Figure 8 Effect of various cytokines and oestrogen receptor ligand and agonists on the release of FGF7 by breast fibroblasts. (A) Purified breast fibroblasts were incubated with different concentrations of IL-1 $\beta$, FGF1, FGF2, FGF8, oestrogen and tamoxifen for 10 days, and the level of FGF7 release into the CM was assayed using ELISA. Each point represents the mean \pm S.E.M. of $n \geq 3$. (B) Purified breast fibroblasts were treated with a range of IL- $1 \beta$ concentrations, $0 \cdot 001,0 \cdot 01,0 \cdot 1,1$ and $10 \mathrm{ng} / \mathrm{ml}$, and the amount of FGF7 released assayed using ELISA. Each point represents the mean \pm S.E.M. of $n \geq 6$.

IL-1 $\beta$ expression could be an important factor in proliferative breast disease. Consistent with this, a role for the inflammatory cytokine IL-1 in stimulating stromal FGF7 production to activate epithelial growth and development via a paracrine mechanism has previously been demonstrated in other tissues, including the skin, cornea and endometrium (Chedid et al. 1994, Finch et al. 1995b, Li \& Tseng 1997, Weng et al. 1997, Li \& Rinehart 1998).

Our results are the first to demonstrate a mitogenic effect of FGF7 on both epithelial and myoepithelial breast cells. This growth factor is, at the present time, the sole FGF known to have similar effects on both cells, since neither FGF1 nor FGF2 induces the proliferation of myoepithelial cells, while both stimulate luminal epithelial cell proliferation (Jackson et al. 1997). This mitogenic effect of FGF7-purified primary cell populations was confirmed by our studies with entire organoids, which showed clear evidence of proliferation of both cell types. These results expand those of Pedchenko \& Imagawa (1998, 2000), who demonstrated that KGF induced stellate outgrowths of colonies of murine epithelial mammary cells in collagen matrix.

In conclusion, our experiments define the critical role of stromally derived FGF7 in breast cell proliferation. We have demonstrated the localisation of FGF7 and its receptor in human breast tissue and have demonstrated its release from breast fibroblasts. Further, we have demonstrated FGF7 to have mitogenic and morphogenic effects 
on both luminal and myoepithelial cells. We postulate it has an important role in lobulo-alveolar growth and possibly differentiation. It is clear that mesenchymalepithelial interactions involving FGF family members have been shown to be important in numerous developmental processes, from the formation of sensory placodes, to the development of teeth (Thesleff \& Sharpe 1997, Ladher et al. 2000). Of particular interest is the observation that normal keratinocyte differentiation in the skin also appears to be regulated by the IL-1 induction of FGF7 as a paracrine factor, which suggests that this mechanism may be widespread (Angel \& Szabowski 2002). Our experiments have characterised an important example of mesenchymal-epithelial interaction which may be critical in the normal development and tissue homeostasis of the mammary gland. Since multistep carcinogenesis models suggest that transformation is often associated with increased response of cells to endogenous growth factors, it is logical to assume stromally derived FGF7 will play a significant role in both malignant transformation and tumour pathology in breast cancer.

\section{References}

Angel P \& Szabowski A 2002 Function of AP-1 target genes in mesenchymal-epithelial cross-talk in skin. Biochemical Pharmacology 64 949-956.

Bansal GS, Cox HC, Marsh S, Gomm JJ, Yiangou C, Luqmani Y, Coombes RC \& Johnston CL 1997 Expression of keratinocyte growth factor and its receptor in human breast cancer. British Journal of Cancer 75 1567-1574.

Basilico C \& Moscatelli D 1992 The FGF family of growth factors and oncogenes. Advances in Cancer Research 59 115-165.

Boismenu R \& Havran WL 1994 Modulation of epithelial cell growth by intraepithelial gamma delta T cells. Science 266 1253-1255.

Cardiff RD \& Wellings SR 1999 The comparative pathology of human and mouse mammary glands. Journal of Mammary Gland Biology and Neoplasia 4 105-122.

Chedid M, Rubin JS, Csaky KG \& Aaronson SA 1994 Regulation of keratinocyte growth factor gene expression by interleukin 1. Journal of Biological Chemistry 269 10753-10757.

Emoto H, Tagashira S, Mattei MG, Yamasaki M, Hashimoto G, Katsumata T, Negoro T, Nakatsuka M, Birnbaum D, Coulier F et al. 1997 Structure and expression of human fibroblast growth factor-10. Journal of Biological Chemistry 272 23191-23194.

Finch PW, Cunha GR, Rubin JS, Wong J \& Ron D 1995a Pattern of keratinocyte growth factor and keratinocyte growth factor receptor expression during mouse fetal development suggests a role in mediating morphogenetic mesenchymal-epithelial interactions. Developmental Dynamics 203 223-240.

Finch PW, Lengel C \& Chedid M 1995 b Cloning and characterization of the promoter region of the human keratinocyte growth factor gene. Journal of Biological Chemistry 270 11230-11237.

Fukabori Y, Yan G, Yamanaka H \& McKeehan WL 1994 Rapid induction of keratinocyte growth factor (FGF-7) and beta-actin after exposure of prostate stromal cells to androgen. In Vitro Cellular and Developmental Biology. Animal 30A 745-746.

Gomm JJ, Browne PJ, Coope RC, Liu QY, Buluwela L \& Coombes RC 1995 Isolation of pure populations of epithelial and myoepithelial cells from the normal human mammary gland using immunomagnetic separation with Dynabeads. Analytical Biochemistry 226 91-99.
Gomm JJ, Coope RC, Browne PJ \& Coombes RC 1997 Separated human breast epithelial and myoepithelial cells have different growth factor requirements in vitro but can reconstitute normal breast lobuloalveolar structure. Journal of Cellular Physiology 171 11-19.

Guo L, Degenstein L \& Fuchs E 1996 Keratinocyte growth factor is required for hair development but not for wound healing. Genes and Development 10 165-175.

Harris RA, Eichholtz TJ, Hiles ID, Page MJ \& O’Hare MJ 1999 New model of ErbB-2 over-expression in human mammary luminal epithelial cells. International Journal of Cancer 80 477-484.

Hoshikawa M, Ohbayashi N, Yonamine A, Konishi M, Ozaki K, Fukui S \& Itoh N 1998 Structure and expression of a novel fibroblast growth factor, FGF-17, preferentially expressed in the embryonic brain. Biochemical and Biophysical Research Communications 244 187-191.

Imagawa W, Cunha GR, Young P \& Nandi S 1994 Keratinocyte growth factor and acidic fibroblast growth factor are mitogens for primary cultures of mammary epithelium. Biochemical and Biophysical Research Communications 204 1165-1169.

Jackson D, Bresnick J, Rosewell I, Crafton T, Poulsom R, Stamp G \& Dickson C 1997 Fibroblast growth factor receptor signalling has a role in lobuloalveolar development of the mammary gland. Journal of Cell Science 110 1261-1268.

Jacquemier J, Sun ZZ, Penault-Llorca F, Geneix J, Devilard E, Adelaide J \& Birnbaum D 1998 FGF7 protein expression in human breast carcinomas. Journal of Pathology 186 269-274.

Johnston CL, Cox HC, Gomm JJ \& Coombes RC 1995 Fibroblast growth factor receptors (FGFRs) localize in different cellular compartments. A splice variant of FGFR-3 localizes to the nucleus. Journal of Biological Chemistry 270 30643-30650.

Kitsberg DI \& Leder P 1996 Keratinocyte growth factor induces mammary and prostatic hyperplasia and mammary adenocarcinoma in transgenic mice. Oncogene 13 2507-2515.

Koga C, Adati N, Nakata K, Mikoshiba K, Furuhata Y, Sato S, Tei H, Sakaki Y, Kurokawa T, Shiokawa K et al. 1999 Characterization of a novel member of the FGF family, XFGF-20, in Xenopus laevis. Biochemical and Biophysical Research Communications 261 756-765.

Koji T, Chedid M, Rubin JS, Slayden OD, Csaky KG, Aaronson SA \& Brenner RM 1994 Progesterone-dependent expression of keratinocyte growth factor mRNA in stromal cells of the primate endometrium: keratinocyte growth factor as a progestomedin. Journal of Cell Biology 125 393-401.

Ladher RK, Anakwe KU, Gurney AL, Schoenwolf GC \& Francis-West PH 2000 Identification of synergistic signals initiating inner ear development. Science 290 1965-1967.

Li DQ \& Tseng SC 1997 Differential regulation of keratinocyte growth factor and hepatocyte growth factor/scatter factor by different cytokines in human corneal and limbal fibroblasts. Journal of Cellular Physiology 172 361-372.

Li Y \& Rinehart CA 1998 Regulation of keratinocyte growth factor expression in human endometrium: implications for hormonal carcinogenesis. Molecular Carcinogenesis 23 217-225.

Luqmani YA, Bansal GS, Mortimer C, Buluwela L \& Coombes RC 1996 Expression of FGFR2 BEK and K-SAM mRNA variants in normal and malignant human breast. European Journal of Cancer 32A $518-524$.

Mann GB \& Borgen PI 1998 Breast cancer genes and the surgeon. Journal of Surgical Oncology 67 267-274.

Miki T, Fleming TP, Bottaro DP, Rubin JS, Ron D \& Aaronson SA 1991 Expression cDNA cloning of the KGF receptor by creation of a transforming autocrine loop. Science 251 72-75.

Miyamoto M, Naruo K, Seko C, Matsumoto S, Kondo T \& Kurokawa T 1993 Molecular cloning of a novel cytokine cDNA encoding the ninth member of the fibroblast growth factor family, which has a unique secretion property. Molecular and Cellular Biology $134251-4259$ 
Nishimura R, Li W, Kashishian A, Mondino A, Zhou M, Cooper J \& Schlessinger J 1993 Two signaling molecules share a phosphotyrosine-containing binding site in the platelet-derived growth factor receptor. Molecular and Cellular Biology 13 6889-6896.

Ohbayashi N, Hoshikawa M, Kimura S, Yamasaki M, Fukui S \& Itoh N 1998 Structure and expression of the mRNA encoding a novel fibroblast growth factor, FGF-18. Journal of Biological Chemistry 273 18161-18164.

Pedchenko VK \& Imagawa WT 1998 Mammogenic hormones differentially modulate keratinocyte growth factor (KGF)-induced proliferation and KGF receptor expression in cultured mouse mammary gland epithelium. Endocrinology 139 2519-2526.

Pedchenko VK \& Imagawa W 2000 Estrogen treatment in vivo increases keratinocyte growth factor expression in the mammary gland. Journal of Endocrinology 165 39-49.

Peehl DM \& Rubin JS 1995 Keratinocyte growth factor: an androgen-regulated mediator of stromal-epithelial interactions in the prostate. World Journal of Urology 13 312-317.

Peehl DM, Wong ST \& Rubin JS 1996 KGF and EGF differentially regulate the phenotype of prostatic epithelial cells. Growth Regulation 6 22-31.

Pekonen F, Nyman T \& Rutanen EM 1993 Differential expression of keratinocyte growth factor and its receptor in the human uterus. Molecular and Cellular Endocrinology 95 43-49.

Rubin JS, Bottaro DP, Chedid M, Miki T, Ron D, Cheon G, Taylor WG, Fortney E, Sakata H, Finch PW et al. 1995 Keratinocyte growth factor. Cell Biology International 19 399-411.

Savagner P, Valles AM, Jouanneau J, Yamada KM \& Thiery JP 1994 Alternative splicing in fibroblast growth factor receptor 2 is associated with induced epithelial-mesenchymal transition in rat bladder carcinoma cells. Molecular Biology of the Cell 5 851-862.

Sugimura Y, Foster BA, Hom YK, Lipschutz JH, Rubin JS, Finch PW, Aaronson SA, Hayashi N, Kawamura J \& Cunha GR 1996 Keratinocyte growth factor (KGF) can replace testosterone in the ductal branching morphogenesis of the rat ventral prostate. International Journal of Developmental Biology 40 941-951.

Tanaka A, Miyamoto K, Minamino N, Takeda M, Sato B, Matsuo H \& Matsumoto K 1992 Cloning and characterization of an androgeninduced growth factor essential for the androgen-dependent growth of mouse mammary carcinoma cells. PNAS $\mathbf{8 9} 8928-8932$.

Thesleff I \& Sharpe P 1997 Signalling networks regulating dental development. Mechanisms of Development 67 111-123.

Ulich TR, Yi ES, Cardiff R, Yin S, Bikhazi N, Biltz R, Morris CF \& Pierce GF 1994 Keratinocyte growth factor is a growth factor for mammary epithelium in vivo. The mammary epithelium of lactating rats is resistant to the proliferative action of keratinocyte growth factor. American Journal of Pathology 144 862-868.

Verdier AS, Mattei MG, Lovec H, Hartung H, Goldfarb M, Birnbaum D \& Coulier F 1997 Chromosomal mapping of two novel human FGF genes, FGF11 and FGF12. Genomics $\mathbf{4 0}$ $151-154$

Weng J, Mohan RR, Li Q \& Wilson SE 1997 IL-1 upregulates keratinocyte growth factor and hepatocyte growth factor mRNA and protein production by cultured stromal fibroblast cells: interleukin-1 beta expression in the cornea. Cornea 16 465-471.

Wilson CA, Ramos L, Villasenor MR, Anders KH, Press MF, Clarke K, Karlan B, Chen JJ, Scully R, Livingston D et al. 1999 Localization of human BRCA1 and its loss in high-grade, non-inherited breast carcinomas. Nature Genetics 21 236-240.

Wilson SE, Weng J, Chwang EL, Gollahon L, Leitch AM \& Shay JW 1994 Hepatocyte growth factor (HGF), keratinocyte growth factor (KGF), and their receptors in human breast cells and tissues: alternative receptors. Cellular and Molecular Biology Research $\mathbf{4 0}$ 337-350.

Yamasaki M, Miyake A, Tagashira S \& Itoh N 1996 Structure and expression of the rat mRNA encoding a novel member of the fibroblast growth factor family. Journal of Biological Chemistry 271 15918-15921.

Yan G, Fukabori Y, McBride G, Nikolaropolous S \& McKeehan WL 1993 Exon switching and activation of stromal and embryonic fibroblast growth factor (FGF)-FGF receptor genes in prostate epithelial cells accompany stromal independence and malignancy. Molecular and Cellular Biology 13 4513-4522.

Yayon A, Zimmer Y, Shen GH, Avivi A, Yarden Y \& Givol D 1992 A confined variable region confers ligand specificity on fibroblast growth factor receptors: implications for the origin of the immunoglobulin fold. EMBO Journal 11 1885-1890.

Zhang Y, Kulp SK, Sugimoto Y, Farrar WB, Brueggemeier RW \& Lin YC 1998a Keratinocyte growth factor (KGF) induces aromatase activity in cultured MCF-7 human breast cancer cells. Anticancer Research 18 2541-2546.

Zhang Y, Sugimoto Y, Kulp SK, Farrar WB, Brueggemeier RW \& Lin YC $1998 b$ Estrogen-induced keratinocyte growth factor mRNA expression in normal and cancerous human breast cells. Oncology Reports 5 577-583.

Received 15 January 2003

Accepted 22 January 2003 